\title{
Study of prevalence of endometrial cancer in patients with adenomyosis uteri
}

\author{
Ahmad Abdel Azim Essmat* \\ Department Obstetrics and Gynecology in El-Shatby Maternity Hospital, Alexandria University, Alexandria, Egypt
}

Received: 24 September 2021

Revised: 24 October 2021

Accepted: 25 October 2021

\section{*Correspondence:}

Dr. Ahmad Abdel Azim Essmat,

E-mail: princeessmat@gmail.com

Copyright: $\odot$ the author(s), publisher and licensee Medip Academy. This is an open-access article distributed under the terms of the Creative Commons Attribution Non-Commercial License, which permits unrestricted non-commercial use, distribution, and reproduction in any medium, provided the original work is properly cited.

\section{ABSTRACT}

Background: The aim of the study was to evaluate the prevalence of adenomyosis in endometrial cancer patients and to determine the frequency of adenomyosis and endometrial cancer at hysterectomy specimens.

Methods: This study was carried out retrospectively on pathologic specimens of hysterectomies. A total of 98 women in the period May 2020 to January 2021enrolled to the study. All pathologies seen in hysterectomy specimens were noted. The frequency of adenomyosis and the accompanying pathologies were determined. These women were categorized into two groups according to the cause of hysterectomy. The incidence of adenomyosis was analyzed together with the endometrial cancer.

Results: The incidence of adenomyosis was $22 \%$ at hysterectomy specimens. There was no statistically significant difference between the mean age of the two groups $(\mathrm{p}=0.002 *)$. There were 22 cases with adenomyosis and the only pathologic finding was adenomyosis, in $22.7 \%$ of cases. The most common accompanying pathologies with adenomyosis were uterine myomas in $95 \%$ and on significant association was found in cases of endometrial carcinoma. Conclusions: There is no evidence that adenomyosis increases the risk of endometrial cancer as there is no statistically significant difference found between the group with and the group without adenomyosis in terms of coexistence with endometrial carcinoma.

Keywords: Adenomyosis, Endometrial carcinoma, Abdominal hysterectomy, Uterine myoma

\section{INTRODUCTION}

Adenomyosis uteri is defined as the presence of endometrial glands and stroma within the myometrium which may be localized or diffuse. ${ }^{1}$ Adenomyosis is an estrogen-dependent disorder that may be associated with other estrogen dependent condition like liomyoma, polycystic ovarian syndrome, endometrial hyperplesia and endometrial cancer. ${ }^{2}$ Adenomyosis is asymptomatic in nearly $30 \%$ of the cases or it has nonspecific findings in the most of the symptomatic cases. ${ }^{3}$ Endometriosis, adenomyosis and uterine fibroids share the common pathophysiology with some gynecologic malignancies such as ovarian and endometrial cancer and there is growing evidence that these benign diseases may undergo malign transformation. ${ }^{4}$ Several studies have documented the co-existence of endometrial cancer and adenomyosis in hysterectomy specimens in an incidence ranged from 16 to $34 \% .^{5}$

It has been reported that adenomyosis is associated with endometrial cancer and it was found that the incidence of these two conditions in hysterectomy patients changed from $10 \%$ to $70 \%{ }^{6}$ The mechanism of the development of endometrial cancer in patients with adenomyosis is poorly understood. Previous studies have reported that adenomyosis can undergo malignant transformation and may be a precursor lesion to adenocarcinoma of the endometrium. ${ }^{7}$ However, no study has demonstrated the natural transformation of adenomyosis to adenocarcinoma. 
There is a frequent association between adenomyosis and other estrogen dependent benign diseases such as endometrial polyps, anovulation, hyperplasia, lieomyomas suggesting that hyperestrogenic state may share the common pathogenesis of these gynecological diseases and endometrial cancer. It has been found that annexin A2 is a key mediator in endometrial tissue growth, metastasis, and angiogenesis.

The p53 positivity was found in hyperplastic and atypical epithelia of carcinoma in adenomyotic patients. ${ }^{8}$ It has been reported that endometrial cancer in association with adenomyosis is associated with more favorable prognosis than in non-adenomyotic uteri, this was attributed to low grade pathology and lower incidence of myometrial invasionIt is also has been found that there was a close relationship between adenomyosis and lower tumor grade, less myometrial invasion, negative lymphovascular space invasion and negative lymph nodes. ${ }^{6,9}$ This result shows that endometrioid tumor with adenomyosis are hormonally responsive, well differentiated, and more likely to be diagnosed earlier while it would be still confined to uterus. ${ }^{4}$ The association between endometrial cancer and adenomyosis is still debated, adenomyosis is found in 10 to $18 \%$ of endometrial cancer specimen at final histology after hysterectomy. ${ }^{10}$

There is a growing evidence that these two diseases share several altered molecular pathways, which lead to increased angiogenesis, abnormal tissue growth, and invasion. Both disorders are associated with a local microenvironment characterized by high level of vascular endothelial growth factor, platelet-derived growth factor, increased production of reactive species of oxygen and pro-inflammatory cytokines, KRAS mutations and, to a lesser extent, progesterone-resistance, epithelialmesenchymal transition and fibroblast-to-myofibroblast trans-differentiation. ${ }^{11} \quad$ Interestingly, accumulating evidence suggests that EC may arise due to incessant proliferative stress of endometrial stromal cells at the junctional zone endometrium. ${ }^{12}$ However, current evidence is not sufficient to draw any definitive conclusion on whether adenomyosis is to be a precursor and/or a risk factor of endometrial cancer. ${ }^{13}$

\section{Aim}

The aim of the study was to evaluate the prevalence of adenomyosis in endometrial cancer patients and to determine the frequency of adenomyosis and endometrial cancer at hysterectomy specimens.

\section{METHODS}

This was a retrospective cohort study performed in ElShatby Maternity University hospital, at the department of gyne-oncology, in Alexandria Egypt, during the period from May 2020 to January 2021. We retrospectively analyzed all cases (total 98 cases) the undergone abdominal hysterectomy for benign lesions and for malignant endometrial cancer.

The inclusion criteria were all cases undergone total abdominal hysterectomy for endometroid adenocarcinoma, with no age limit. Also, all cases cases with adenomyotic uteri with or without other utrine pathologies were included in the study. All cases of abdominal hysterectomy done for ovarian masses or cancer other than endometrial cancer. As well as all cases hysterectomies not done by open surgery (laparoscopic and vaginal hysterectomy cases) were excluded from the study. The study was done after approval of ethics committees.

\section{Statistical analysis}

The data was collected and entered into the personal computer. Statistical analysis was done using Statistical Package for Social Sciences (SPSS version 22) software.

\section{Statistical test}

Arthematic mean, standard deviation, for normally distributed data, comparison between two independent population were done using independent t-test. While for categorized parameters Chi square test was used. To study the association between each two variables person correlation coefficient was used. The level of significant was 0.05 .

Patients were grouped to two groups in terms of the cause of abdominal hysterectomy (benign and malignant endometrial cancer). In each group, the following data were collected: patients demographic data including age, parity status, menopausal status, ultrasonogrraphic findings (including measurement of endometrial thickness and criteria of adenomyosis by ultrasound), indication of hysterectomy and associated pathology (including endometrial polypi, hyperplesia, lieomyomas, chronic cervicitis, etc.) and finally presence or absence of adenomyosis in final histopathological report. Adenomyosis is defined as the presence of endometrial glands and stroma within the myometrium. Post-operative histopathological diagnosis of adenomyosis was made both by the naked eye by means of determining trabecular and hemorrhagic areas in the myometrium, and pathologically by the way of establishing the presence of ectopic endometrial glandular or stromal tissue.

\section{RESULTS}

In this study, we evaluated pathological results of total 98 post-hysterectomy specimens. 40 cases $(40.8 \%)$ were done for benign causes, while 58 cases $(59.18 \%)$ were done for malignant endometrial cancer. The mean age of benign group was 49 year, while the mean age for malignant group was 60 years (Table 1). Most of benign cases (70\%) were done in pre-menopauseal age, while $93.1 \%$ of malignant endometrial cancer patients were in post-menopausal age 
group. The incidence of adenomyosis in hysterectomy specimens was $30 \%$ in benign groups, while it was $17.2 \%$ in malignant group. The incidence of adenomyosis in all hysterectomy specimens (both benign and malignant group) was $22.4 \%$ (Table 2). Pure adenomyosis was found in 22/98 cases $(22.44 \%)$. The remaining cases had associated pathological lesions such as uterine myoma, endometrial polyps, endometrial hyperplesia and chronic cervicitis. The most common associated pathological lesions were lieomyomas in $95 \%$ of benign group, and in $37.9 \%$ in malignant endometrial group. Endometrial hyperplasia was the most common associated pathological finding with the malignant endometrial group which represented $72.4 \%$ in these cases (Table 3).

Table 1: Comparison between the two studied groups regarding demographic and basic clinical data.

\begin{tabular}{|c|c|c|c|}
\hline Parameters & Benign group ( $\mathrm{N}=40)$ & Malignant group ( $N=58)$ & P value \\
\hline \multicolumn{4}{|l|}{ Age (years) } \\
\hline Range & $35-70$ & $34-75$ & \multirow{2}{*}{$0.002 *$} \\
\hline Mean \pm SD & $49.0 \pm 8.3$ & $60.2 \pm 9.2$ & \\
\hline \multicolumn{4}{|l|}{ Mean gravidity } \\
\hline Range & $0-10$ & $0-11$ & \multirow{2}{*}{0.815} \\
\hline Mean \pm SD & $4.0 \pm 2.7$ & $4.1 \pm 2.8$ & \\
\hline \multicolumn{4}{|l|}{ Mean parity } \\
\hline Range & $0-10$ & $0-9$ & \multirow{2}{*}{0.989} \\
\hline Mean \pm SD & $3.7 \pm 2.5$ & $3.6 \pm 2.4$ & \\
\hline \multicolumn{4}{|l|}{ Mean previous abortion } \\
\hline Range & $0-2$ & $0-2$ & \multirow{2}{*}{0.240} \\
\hline Mean \pm SD & $0.3 \pm 0.6$ & $0.5 \pm 0.7$ & \\
\hline \multicolumn{4}{|l|}{ Mode of delivery } \\
\hline No. of previous deliveries & $34(85 \%)$ & $50(86.2 \%)$ & \multirow{3}{*}{0.465} \\
\hline NVD & $28(70 \%)$ & $46(79.3 \%)$ & \\
\hline $\mathrm{CS}$ & $6(15 \%)$ & $4(6.9 \%)$ & \\
\hline \multicolumn{4}{|l|}{ Menopausal status } \\
\hline Pre-menopause & $28(70.0 \%)$ & $4(6.9 \%)$ & \multirow{2}{*}{$0.0016^{*}$} \\
\hline Post-menopause & $12(30.0 \%)$ & $54(93.1 \%)$ & \\
\hline
\end{tabular}

Note: *-Statistically significant difference.

Table 2: Incidence of adenomyosis in cases of total abdominal hysterectomy in the two studied groups.

\begin{tabular}{|c|c|c|c|c|c|c|}
\hline \multirow{2}{*}{ Adenomyosis } & \multicolumn{2}{|c|}{ Benign group $(\mathrm{N}=40)$} & \multicolumn{2}{|c|}{ Malignant group $(\mathrm{N}=58)$} & \multicolumn{2}{|c|}{ Total $(\mathbf{N}=98)$} \\
\hline & $\mathbf{N}$ & $\%$ & $\mathbf{N}$ & $\%$ & $\mathbf{N}$ & $\%$ \\
\hline Present & 12 & 30.0 & 10 & 17.2 & 22 & 22.4 \\
\hline Absent & 28 & 70.0 & 48 & 82.8 & 76 & 77.6 \\
\hline P value & 0.1 & & & & & \\
\hline
\end{tabular}

Note: N.S.- Not significant.

Table 3: Associated pathological findings in studied groups.

\begin{tabular}{|lllll|}
\hline & Benign group & \multicolumn{3}{c|}{ Malignant group } \\
\hline Pathological findings & $\mathbf{N}$ & $\mathbf{\%}$ & $\mathbf{N}$ & \% \\
\hline Leimyomas & 38 & 95 & 22 & 37.9 \\
\hline Chronic cervicitis & 30 & 75 & 11 & 18.9 \\
\hline Edenomyosis & 12 & 30 & 10 & 17.24 \\
\hline Endometrial hyperplesia & 12 & 30 & 42 & 72.4 \\
\hline
\end{tabular}

\section{DISCUSSION}

Adenomyosis is a benign disorder that is characterized by the presence of endometrial glands and stroma within the myometrium. It has been reported that adenomyosis is associated with increased risk endometrial cancer. ${ }^{6}$ The mechanism of the development of endometrial cancer in patients with adenomyosis remains unclear. Previous reports have suggested that adenomyosis can undergo malignant transformation and may be a precursor lesion to endometrial cancer. ${ }^{7}$

However, there is no study has proved transformation of adenomyosis to adenocarcinoma. There is a frequent association between adenomyosis and other estrogen dependent benign disorders such as endometrial polypi, 
endometrial hyperplasia, lieomyomas suggesting that hyperestrogenic state may share these common diseases of these gynecological diseases and endometrial cancer. ${ }^{8}$

Some studies state that although adenomyosis is a totally benign condition, it can be a precursor for lesion for endometrial cancer and arising from uterine adenomyosis with or without endometrial involvement. ${ }^{14,15}$ Koshiyama et al showed that the adenocarcinoma ratio was $16 \%$ in cases with adenomyosis. ${ }^{16}$ This was in accordance with our study as we found a nearly similar percent. In our study we found that the $17.24 \%$ of patients with endometrial cancer have adenomysis.

In the literature, the reported incidence of adenomyosis in hysterectomy specimens is between $5 \%$ and $70 \% .{ }^{17}$ Our study demonstrated that the incidence of adenomyosis in all cases of abdominal hysterectomy was $22 \%$. Despite of this knowledge, the exact incidence of adenomyosis still can-not be known because the diagnosis of adenomyosis needs histo-pathological confirmation. ${ }^{18}$

Several studies have shown an increased risk of adenomyosis with an increasing parity which are thought to be due to disruption of the barrier between basal endometrium and the myometrium. ${ }^{17}$ The rate of multiparity in our study group was $86.2 \%$ with the diagnosis of adenomyosis which is much more than in nulliparous patients (Table 1).

Cases with adenomyosis are rarely isolated cases. Most of them are accompanied with additional pathologies. Gün et al found that the most frequent accompanying pathologies are uterine myomas $(95 \%, 37.9 \%$ in benign group and malignant endometrial group respectively), endometrial polyps $(2.3 \%)$, hyperplasia $(10.5 \%)$ and endometrial adenocarcinoma $(1.4 \%) \cdot{ }^{19,20}$

Similar results were found in our study. We found that myomas were the most commom pathology associated with adenomyosis. Uterine myomas were the most commonly associated pathology in benign group. It was found in $95 \%$ of cases and in $37.9 \%$ of malignant endometrial group. The most common pathology associated with malignant endometrial group was endometrial heperplesia which was found in $72.4 \%$ of cases (Table 3).

There is no evidence that supports that adenomyosis is a neoplastic process or that shows that there is a relationship between it and endometrial cancer except for associated hyperestrogenemia. ${ }^{4}$ Gün et al also reached a similar concusion. He states that there is no association emerged between endometrial carcinoma and frequency of adenomyosis. ${ }^{20}$ Similar results had been proved in our study.

We did not face any limitation during performance of this study except for collection of data and pathology reports.

\section{CONCLUSION}

There is no evidence that adenomyosis increases the risk of endometrial cancer as there is no statistically significant difference found between the group with and the group without adenomyosis in terms of coexistence with endometrial carcinoma. It is also noted that endometrial cancer that occurs in adenomyotic uteri have also better prognosis than that occurs in non-adenomyotic ones, (owing to thicker myometrium that decreases the incidence of myometrial invasion), being more well differentiated, and lower tumor grade thus having a more favorable prognosis.

\section{Funding: No funding sources}

Conflict of interest: None declared

Ethical approval: The study was approved by the Institutional Ethics Committee

\section{REFERENCES}

1. Frankl O. Adenomyosis uteri. Am J Obstet Gynecol. 1925;10:680-4.

2. Parazzini F, Mais V, Cipriani S, Busacca M, Venturini $\mathrm{P}$, GISE. Determinants of adenomyosis in women who underwent hysterectomy for benign gynecological conditions: results from a prospective multicentric study in Italy. Eur J Obstet Gynecol Reprod Biol. 2009;143(2):103-6.

3. Peric H, Fraser IS. The symptomatology of adenomyosis. Best Pract Res Clin Obstet Gynaecol. 2006;20(4):547-55.

4. Verit FF, Yucel O. Endometriosis, leiomyoma and adenomyosis: the risk of gynecologic malignancy. Asian Pac J Cancer Prev. 2013;14(10):5589-97.

5. Koshiyama M, Okamoto T, Ueta M. The relationship between endometrial carcinoma and coexistent adenomyosis uteri, endometriosis externa and myoma uteri. Cancer Detect Prev. 2004;28(2):94-8.

6. Musa F, Frey MK, Im HB, Chekmareva M, Ellenson LH, Holcomb K. Does the presence of adenomyosis and lymphovascular space invasion affect lymph node status in patients with endometrioid adenocarcinoma of the endometrium? Am J Obstet Gynecol. 2012;207(5):417.

7. Mittal KR, Barwick KW. Endometrial adenocarcinoma involving adenomyosis without true myometrial invasion is characterized by frequent preceding estrogen therapy, low histologic grades, and excellent prognosis. Gynecol Oncol. 1993;49(2):197201.

8. Abushahin N, Zhang T, Chiang S, Zhang X, Hatch K, Zheng W. Serous endometrial intraepithelial carcinoma arising in adenomyosis: a report of 5 cases. Int J Gynecol Pathol. 2011;30(3):271-81.

9. Ismiil N, Rasty G, Ghorab Z, Mozes S, Bernardini M, Ackerman I, et al. Adenomyosis involved by endometrial adenocarcinoma is a significant risk factor for deep myometrial invasion. Ann Diagn Pathol. 2007;11(4):252-7. 
10. Vercellini P, Viganò $\mathrm{P}$, Somigliana E, Daguati $\mathrm{R}$, Abbiati A, Fedele L. Adenomyosis: epidemiological factors. Best Pract Res Clin Obstet Gynaecol. 2006;20(4):465-77.

11. Inoue S, Hirota $\mathrm{Y}$, Ueno $\mathrm{T}$, Fukui $\mathrm{Y}$, Yoshida E, Hayashi $\mathrm{T}$, et al. Uterine adenomyosis is an oligoclonal disorder associated with KRAS mutations. Nat Commun. 2019;10(1):5785.

12. Tanos V, Lingwood L, Balami S. Junctional Zone Endometrium Morphological Characteristics and Functionality: Review of the Literature. Gynecol Obstet Invest. 2020;85(2):107-17.

13. Couto D, Mota F, Silva T, Oliveira C. Adenocarcinoma arising in adenomyosis: report of an unusual case. Acta Obstet Gynecol Scand. 2004;83(4):406-8.

14. Koshiyama M, Suzuki A, Ozawa M, Fujita K, Sakakibara A, Kawamura M, et al. Adenocarcinomas arising from uterine adenomyosis: a report of four cases. Int J Gynecol Pathol. 2002;21(3):239-45.

15. Colman HI, Rosenthal AH. Carcinoma developing in areas of adenomyosis. Obstet Gynecol. 1959;14:3428.
16. Koshiyama M, Okamoto T, Ueta M. The relationship between endometrial carcinoma and coexistent adenomyosis uteri, endometriosis externa and myoma uteri. Cancer Detect Prev. 2004;28(2):94-8.

17. Parazzini F, Mais V, Cipriani S, Busacca M, Venturini $\mathrm{P}$, GISE. Determinants of adenomyosis in women who underwent hysterectomy for benign gynecological conditions: results from a prospective multicentric study in Italy. Eur J Obstet Gynecol Reprod Biol. 2009;143(2):103-6.

18. Ferenczy A. Pathophysiology of adenomyosis. Hum Reprod Update. 1998;4(4):312-22.

19. Bergeron C, Amant F, Ferenczy A. Pathology and physiopathology of adenomyosis. Best Pract Res Clin Obstet Gynaecol. 2006;20(4):511-21.

20. Gün I, Oner O, Bodur S, Ozdamar O, Atay V. Is adenomyosis associated with the risk of endometrial cancer? Med Glas. 2012;9(2):268-72.

Cite this article as: Essmat AAA. Study of prevalence of endometrial cancer in patients with adenomyosis uteri. Int J Reprod Contracept Obstet Gynecol 2021;10:4352-6. 